\title{
A LEI 10.639/03 E AS RELAÇÕES ÉTNICO-RACIAIS NO AMBIENTE
}

\author{
ESCOLAR: MUDANÇAS E PERMANÊNCIAS
}

\section{LAW 10.639/03 AND THE ETHNIC-RACIAL RELATIONS IN THE SCHOOL ENVIRONMENT: CHANGES AND STAYS}

\author{
Nívea Maria Araújo Santana \\ Mestra em Educação pela Universidade Estadual de Pernambuco, atualmente atua na \\ Gerência Regional de Educação Vale do Capibaribe. Pernambuco - PE - Brasil \\ nmas.wendy@gmail.com
}

\begin{abstract}
Resumo: Nos últimos anos, as mudanças trazidas pela globalização cultural e econômica, que, ao contrário do que se imaginava, vem contribuíndo para um processo cada vez mais acentuado de fragmentação das identidades e fortalecimento das heterogeneidades, assim como a maior organização dos movimentos sociais, tem levado o governo brasileiro a implementar políticas afirmativas, a fim de mitigar as graves assimetrias da nossa sociedade. Nesse contexto, trazer o debate acerca da diferença e da diversidade, buscando promover uma educação "étnico-racial positiva", tornou-se, em muitos sentidos, "dever da escola" e, consequentemente "trabalho do professor". Refletir acerca da eficácia e do alcance de tais medidas, em especial a Lei 10.639/03, leva-nos a procurar conhecer e desdobrar-se de maneira positiva em prática escolar, especialmente no que se refere ao ensino de História e a "pluralidade cultural", presentes nos PCNs.
\end{abstract}

Palavras-chave: Lei 10.639/03. Diversidade. Mudança. Escola.

\begin{abstract}
In recent years, the changes brought about by economic and cultural globalization, which, contrary to what was thought, have contributed to an increasingly pronounced process of fragmentation of identities and strengthening of heterogeneities, as well as the largest organization of social movements, has led the Brazilian government to implement affirmative action policies in order to mitigate the serious imbalances in our society. In this context, bringing the debate on difference and diversity, seeking to promote a "positive ethnic-racial" education has become, in many ways, "school duty" and consequently "teacher's job." Reflect on the effectiveness and scope of such measures, especially the Law 10.639 / 03, leads us to seek to know and unfold in a positive way school practice, especially regarding the history teaching and "cultural plurality" present in the PCNs.
\end{abstract}

Key-words: Law 10.639/03. Diversity. Change. School.

Cadernos de Pós-graduação, São Paulo, v. 17, n. 2, p. 121-140, jul./dez. 2018. 


\section{Introdução}

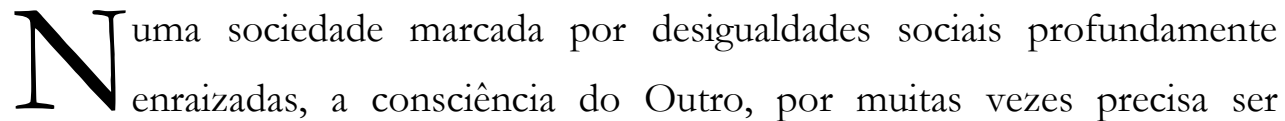
despertada por algum fator externo, uma vez que o consumismo e o individualismo ajudam a acirrar as diferenças culturais, estimulam a competição e criam novos objetos de desejo, padrões de beleza e parâmetros de sucesso numa velocidade nauseante.

Em tal contexto, aceitar e respeitar as diferenças e reconhecer a diversidade como algo positivo é parte de um exercício de reflexão e autoconhecimento que tem início quando entendemos que, a construção da nossa identidade não é um processo solitário e sim, resultado de uma relação muito estreita com as pessoas ao nosso redor, que são responsáveis por nos dar parâmetros, diante dos quais podemos moldar os limites do nosso próprio ser.

O que fica evidenciado nas discussões sobre as relações raciais e a educação, que tem mostrado a importância de se trabalhar na perspectiva de influenciar a dinâmica escolar, evitando a perpetuação e reprodução de discussos depreciadores da identidade de aluno/as, a partir do estímulo ao diálogo e a convivência com as diferenças, reelaborando significados sociamente construídos e confirmando que a prática pedagógica e os princípios culturais precisam ser continuadamente reiventadas e reinvestidas de novos sentidos.

Nessa perspectiva, procedeu-se o projeto de dissertação do Mestrado em Educação, o qual foi motivado pelas nossas observações em sala de aula e nossa inquietação quanto as diferenças e desigualdades nos espaços da escola, onde procuramos conhecer os referenciais dos professores e alunos, bem como, as relações 
que se estabelecem na prática pedagógica sobre a diversidade na sala de aula, com enfase para a presentaça dos afro-brasileiros.

Buscando, nesse ínterim, refletir até que ponto os objetivos almejados com a implantação da Lei 10.639/03, conseguiram sair do campo da "retórica" e influenciar na praxis a adoção de uma educação inclusiva, principalmente quando a euforia com relação a mesma já aferreceu e novas pautas ocupam o interesse imediato da mídia.

\section{Educação e diversidade no contexto educacional brasileiro: breve trajetória}

Nas últimas décadas conceitos como multiculturalidade e interculturalidade vem ganhando espaço nas discussões acerca da Educação em vários países do mundo, chama a atenção, porém, que isso ocorra justamente quando a instituição escolar passa por seu período de maior fragilidade, quando a sua própria relevância vem sendo questionada, fazendo com que o desafio dos educadores em relação implementação de uma educação multi-intercultural seja ainda mais acentuado, principalmente levando-se em conta as vissicitudades de cada país, uma vez que esse não é um fenômeno isolado.

No caso brasileiro, cujo sistema educacional possui uma história de acentuada hierarquização e elitização, que contribuiu para a exclusão de boa parte da população dos bancos escolares, ajudando a perpetuar o status quo das elites, a visão propedéutica e tecnicista do ensino, principalmente do Ensino Médio ${ }^{1}$, tem sido alvo de duras críticas desde sua institucionalização durante o período imperial, quando entre os poucos privilegiados que podiam ingressar nas intituições educacionais, um número ainda menor conseguia ter acesso ao Ensino Secundário².

Com fim da escravidão e após a República, a "hierarquização” intensificou-se, ganhando contornos racialistas, como podemos observar nos estudos de (ARANTES, 2014), onde podemos ver que graças a forte influência da medicina higienista, cujos 
principais expoentes bebiam, por sua vez, nas teorias raciais introduzidas no Brasil desde meados do século XIX, ocorreu uma divisão, ainda mais acentuada, entre os alunos, que passaram a ser classificados conforme as "características" do grupo racial no qual eram enquadrados:

Nesse contexto o grupo escolar representou um novo modelo de organização escolar, caracterizado pela seriação com a divisão de alunos por classes, considerando-se a idade e os níveis de conhecimentos que se pretendia fossem homogêneos. (ARANTES, 2014, p. 116).

É que nesse período (a partir da década de 1930) que, ironicamente, o mestiço, até então visto como uma mazela a ser combatida, é eleito como símbolo do Brasil, por representar o ideal da união das três raças que formaram o povo brasileiro (branco, negro e índigena), ajudando a reforçar o mito de que o país seria um modelo de democracia racial, ideia para qual as obras de Gilberto Freire - Casa Grande e Senzala (1933) iriam trazer grande contribuição, formando uma parceria com o Estado Novo (1937-1945), que possibilitou uma aliança perfeita para alimentar o imaginário social do "mito da democracia racial" e da "união das três raças".

Apenas durante a década de 1970, o processo de organização dos professores começa a se articular no interior do movimento social organizado e a escola e o ensino tradicional passam a ser alvo de críticas e contestações. A pressão exercida por esses movimentos faz com que tenha início uma política governamental voltada para “universalização da Educação”, influenciada, sobretudo pela Lei 5.692/1971³, a paritr da qual serão feitas revisões nas legislação pertinente ao ensino e iniciam-se processos de reformas dos currículos.

Tal proposta, entrentanto, acaba por trazer uma dicotomização ainda mais acentuada para o Ensino Médio, onde 
As redes públicas de ensino técnico federal e as redes estaduais como a de São Paulo, elitizadas por meio da seletividade promovida pelos "vestibulinhos" e beneficiadas com políticas que favoreciam melhores condições de trabalho e remuneração a seus professores, conseguiram promover maior qualidade no ensino do que aquela oferecida pelas escolas de ensino médio denominadas "regulares", destinadas à população trabalhadora. (BRASIL, 2013, p. 20-21).

Essa divisão entre escolas públicas e escolas privadas, por sua vez, causa um distanciamento ainda mais acentuado das condições democráticas nas escolas, onde ao contrário do que se precisava, acentua-se a "ressegregação nas escolas", uma vez que,

Para contornar esse problema [da inclusão de universalização do ensino público] as famílias ricas enviam seus filhos para escolas privadas, instituições que foram criadas geralmente fora dos centros urbanos, onde mais e mais famílias estão se mudando para espacapar da violência, guetização e a sensação de insegurança. (SANTIAGO, 2013, p. 59).

De igual modo, mesmo a Constituição de 1988 e a promulgação da LDB, bem como todas as medidas tomadas durante a década de $1990^{4}$, não vão ser capazes de trazer mudanças estruturais significativas no conceito igualdade e justiça social.

Essa dificuldade de produzir ressignificações efetivas nas relações sociais, levou Fry (2005, p.227) a afirmar que essas medidas "são usadas para fortalecer os direitos e liberdades individuais conforme o racismo e o racialismo, não representam mudanças marcantes na política antiga e estão em consonância com os ideais de 'democracia racial"”.

Assim, embora reconhecendo que a Lei $10.639 / 03^{5}$ tenha trazido mudanças significativas para o currículo da disciplina escolar História, notório, como apontam Torres e Ferreira (2014, p. 89) por “apresentar tradições curriculares consolidadas e que trazem como marca importante o protagonismo do homem branco em detrimento 
A LEI 10.639/03 E AS RELAÇÕES ÉTNICO-RACIAIS NO AMBIENTE ESCOLAR: MUDANÇAS E

PERMANÊNCIAS

ao processo vivenciado pelos africanos em nossa sociedade", acreditamos ser necessário refletir acerca do alcance e das limitações que a Lei, enquanto política afirmativa do governo brasileiro, em relação à promoção mudanças efetivas no modo como ocorrem as relações "étnico-raciais" entre os indivíduos, tendo a Escola como palco e termômetro que permite aferir a eficácia ou não de tais iniciativas.

Para tanto, partimos do princícpio que a imposição legal por si só, não é capaz de fomentar relações "etnico-raciais" positivas nem a valorização das diversas identidades dos alunos dentro das escolas, sem que haja um processo de formação dos docentes que leve a uma ressignificação da forma como os mesmos enxergam e trabalham a diversidade na sala de aula.

\section{A Lei 10.639/03 e o lugar da diferença na escola}

A busca para galgar posições no ranking de avaliações, como por exemplo, o Programa para Avaliação Internacional de Estudantes (PISA), acaba levando à conclusões duvidosas acerca da diversidade e da multiculturalidade na sala de aula, sendo esses fatores transformados em problemas e entraves as metas traçadas pelos gestores das políticas públicas; além de estimular e fortalecer o uso de práticas educacionais homogeneizantes, posto que só o resultado interessa e toda heterogeneidade dos alunos é diluida quando os mesmos são transformados em números para compor estatísticas.

Essa posição vem corroborar as reflexões tecidas por (TORRES; FERREIRA, 2014) acerca do papel da Lei 10.639/03 no currículo da disciplina escolar História, sob o argumento de que a mudança implica num processo de negociação entre o passado e o presente, o antigo e o novo ${ }^{6}$, que nem sempre será contraditório, ao contrário, a mudança pode surgir como recurso para manter a estabilidade de quem já está no 
poder, citando, como disparador para a discursão a seguinte frase de Hanna Arendt: "nenhuma mudança política parece capaz de realizar qualquer coisa de inteiramente novo” (TORRES; FERREIRA, 2014, p. 83).

Tais observações levam-nos a questionar os limites e as limitações da Lei 10.639/03, principalmente no tocante a capacidade de execução e a eficácia da mesma, uma vez que, apesar de amplamente discutida, parece que não houve uma reflexão sobre a formação adequada de professores, bem como não se percebe outros meios que possibilitem mensurar efeitos que impacte o ensino.

Por sua vez, uma leitura mais aprofundada tanto do texto da lei, quanto das Diretrizes Nacionais para Educação Básicas das Relações Étnico-Raciais (DCNEB), que vieram normatizar os princípios legais, mostra uma série de divergências com relação à utilização de categorias como “África”, "afro-brasileiro" e "negro", por exemplo, que atraem críticas vorazes, principalmente dos grupos que não concordam com a teoria do "panafricanismo" e veem o termo "África" como reducionista e homogeneizante, que não é capaz de traduzir a diversidade de povos e culturas do continente africano ou mesmo entender a influência deste na formação da sociedade brasileira

Nesse contexto, diante da diversidade de interpretações das diferenças e das apropriações de teorias, muitas delas deterministas, acaba-se quase sempre, optando-se por princípios determinados pelo mito do "embranquecimento racial" ou pela valorização do país "mestiço" da visão freyriana.

Esses exemplos ilustram algumas das contradições existentes na Lei 10.639/03 e nos remetem a (LACLAU, 2011) e o conceito de cadeia de equivalências que usa para tentar explicar o mundo pós-moderno, onde as certezas e verdades absolutas da modernidade, cederam lugar para a dúvida e as polissemias fazem com que categorias como liberdade, democracia, política e igualdade, tornem-se "significantes vazios"7. 
Sob tal perspectiva, segundo Stoer e Cortesão (1999, p. 14) “[...] o Estado se sente pressionado a legitimar aos olhos dos cidadãos a sua actuação, as suas opções e, portanto, as relações que estabelece com as diferentes instituições" e assim, podemos dizer que o texto presente na Lei é resultado desse processo de negociação, no qual determinado grupo (movimentos negros), conseguiu fazer valer suas reividicações em detrimento dos demais, inclusive, dos indígenas ${ }^{8}$.

Esse "deslocamento" do centro de poder, faz com que Estado e sociedade, sejam "forçados a fazer uma <gestão controlada>", de dois fenômenos diretamente ligados ao processo de moderniade: a desigualdade e a exclusão, pois,

[...] apesar de a desigualdade e a exclusão estarem indissociavelmente ligadas ao processo de desenvolvimento capitalista, essa mesma sociedade e Estado não podem deixar transparecer que, eventualmente, têm até alguma possibilidade de tirar partido delas. (STOER; CORTESÃO, 1999, p. 13-14)

E assim, podemos inferir que ações como as políticas afirmativas adotadas pelo Estado brasileiro nas últimas décadas, visam à estabilidade da sociedade e do próprio governo, uma vez que "a função primordial do Estado é a manutenção dele mesmo" (SCHURSTER, 2015) ${ }^{9}$, ainda que para isso seja necessário promover mudanças na organização dessa mesma sociedade, o que torna a Escola peça chave em tal processo.

Desse modo, uma vez que outras instituições (família, igreja, militar) vem perdendo espaço dentro da sociedade e sendo a Escola "uma das poucas instituições que, $[\ldots]$ reúne e socializa grandes grupos etários $[\ldots]$ será nela que depositam algumas expectativas de que, por exemplo, se possa manter e reproduzir a cultural nacional” (STOER; CORTESÃO, 1999, p. 20). Entretanto, como falar em "cultura nacional” numa época onde multiculturalidade virou palavra de ordem? Onde as identidades são "fluídas" e a heterogeneidade avança juntamente com o processo de globalização? 
Quando nos reportamos para um dispositivo legal, ou seja, a Lei 10.639/03, que de forma vertical e hierarquizada vem impor/propor uma transformação significativa (mesmo que necessária) no modus operandi de pessoas inseridas num contexto social onde a questão racial é tão complexa quanto no Brasil, nos inquirimos quando e si essa lei irá levar a uma práxis efetiva.

Afinal, a incumbência de cumprir a lei (para não falarmos em 'missão') é dada a Escola, instituição que ao longo de sua existência "passou por mutações que a fizeram caminhar 'de um modelo de certezas para um modelo de promessas e, finalmente para um terceiro, marcado por incertezas"” (KOFF, 2012, p. 173) sem contudo, ofereceremse os aportes necessários para tanto.

E assim, a urgência em reparar 'injustiças' históricas, bem como atender as demandas da sociedade, faz com que as medidas tomadas sejam de difícil implantação, ficando muitas vezes apenas na esfera política ou demonstrando um efeito "cosmético" e lenvando-nos a crer, como colocado por Torres e Ferreira (2014, p. 92), que "[...] a inserção de 'novas' questões envolvendo a História da África e cultura afro-brasileira e africana no país, se ancora em tradições estabilizadas que, em grande parte, foram produzidas na lógica que desejamos combater".

Não se trata, porém, de ignorar os avanços proporcionados pela implementação desta Lei, a qual,

[...] reúne elementos sugestivos de mudanças importantes no ensino da disciplina escolar História, em virtude de ela apresentar tradições curriculares consolidadas e que trazem como marca importante o protagonismo do homem branco em detrimento dos processos vivenciados pelos africanos em nossa sociedade. (TORRES; FERREIRA, 2014, p. 89).

Nem desprezar a notoriedade que esse instrumento legal ganhou junto aos meios de comunicação, nos centros acadêmicos e nas escolas no geral, que foram levados a discutir temas relacionados ao racismo e a discriminação, os quais 
A LEI 10.639/03 E AS RELAÇÕES ÉTNICO-RACIAIS NO AMBIENTE ESCOLAR: MUDANÇAS E PERMANÊNCIAS

representavam tabus dentro da sociedade brasileira, principalmente devido a autoimagem de mestiçagem fomentada, desde a década de 1930 e ao já citado mito da democracia racial ${ }^{10}$, que ocupou o lugar da política de embraquecimento no discurso oficial, mostrando assim o desafio estabelecido na escola, como espaço privilegiado para estudar essa pluralidade cultural e as diversidades de idéias.

Não podemos, entretanto, fugir ao debate sobre a implantação de uma lei com tantas implicações para a sociedade, aceitando-a sem fazer maiores questionamentos acerca dos interesses envolvidos em sua elaboração e a quem a mesma beneficia, uma vez que sua redação, embora controversa em muitos pontos, como já dito antes, é bem clara ao indicar qual "minoria" deve ser valorizada.

Fica claro que é preciso combater o preconceito racial, assim como todo tipo de atitude discriminatória, principalmente no âmbito educacional, mas, e aí nos remetemos a Hanna Arendt novamente, uma decisão política, mesmo que traduza os anseios de uma parte da sociedade, pode garantir a efetivação de mudanças reais nas relações sociais? Ou ficamos apenas no campo do discurso e da retórica?

\section{Em busca de outros princípios pedagógicos}

Os questionamentos acima levantados, bem como a convivência diária com os demais professores e com os alunos, do turno da noite, da Escola Pe. Nicolau Pimentel, localizada no munícipio de Limoeiro, agrestre pernambucano, onde lecionamos e tivemos a oportunidade de presenciar vários momentos em que questões relacionadas à diferença e a diversidade foram motivos de conflitos, fizeram com que déssemos início a presente pesquisa, com a finalidade de analisarmos os efeitos da Lei 10.639/03 na forma como os alunos constroem suas relações com a diversidade e a diferença no ambiente escolar. 
Para nortear nossa pesquisa escolhemos a Lei 10.639/03 como categoria central, em virtude de acreditarmos que ao trazer o Ensino da História e da Cultura Afro-Brasileira e Africana para o currículo da Educação Básica do país, esta Lei abriu caminho não só para o debate acerca das questões relacionadas ao racismo e a discrimininação dos afro-brasileiros, como também deu maior visibilidade para a presença da diferença na Escola.

Outra categoria de análise que elegemos foi a alteridade, ou seja, a capacidade de entender o que é o Outro, aceitando-o como ele é, e não como nós gostaríamos que fosse, conceito que consideramos essencial ao lidarmos com a diferença e a diversidade na sala de aula.

Como nosso objeto de pesquisa eram os alunos da Educação Básica, mas precisamente do Ensino Normal Médio ${ }^{11}$, optamos por utilizar como aborgagem metodologica a pesquisa-ação, por esta “desenvolver-se através de um processo onde os agentes sociais <implicados> interagem tanto no conhecimento como na acção podendo < construir conhecimentos que não seriam possíveis numa relação de exterioridade face à situação explicada >”. (STOER; CORTESÃO, 1999, p. 45).

Com isso em mente, formamos um grupo focal composto pelos/as alunos/as do $4^{\mathrm{a}}$ ano A do Ensino Normal Médio, da já mencionada escola, sendo a turma e, consequentemente o nosso grupo focal, formado por 12 estudantes, três rapazes e nove moças, com idades que variam entre 16 e 21 anos, todos egressos de escolas públicas.

A escolha por esta turma deu-se por indicação dos próprios docentes da escola, que ao ouvirem a natureza da pesquisa que pretendiamos realizar, foram unissonos em apontar a turma do $4^{\mathrm{a}} \mathrm{ENM}$ - A, por serem, segundo eles (professores) alunos/as cuja formação fora feita toda no Ensino Normal Médio e, portanto, eram o exemplo do modelo de professores que o curso estava preparando. 
Até o momento de produção deste artigo, o nosso grupo focal já realizou quatro encontros, sempre tendo como questão disparadora a Lei 10.639/03 e a presença da diferença e da diversidade na sala de aula. Desde o primeiro encontro buscamos, dentro da proposta da pesquisa-ação, estimular os/as alunos/as a externarem suas opiniões acerca do tema, levamos vídeos e textos, procurando observar e perceber suas reações.

O primeiro fato que nos chamou a atenção foi a disparidade entre o quantitativo de homens e mulheres na sala de aula, fenômeno que atribuimos a uma consequência do processo de "feminização do magistério" que, segundo (ROSA, 2011) sofreu uma intensificação a partir do ano de 1908 que

[...] estaria vinculada ao aumento do número de vagas nas escolas e ao processo de urbanização e industrialização que ampliou as oportunidades de trabalho para os homens. Estes foram em busca de empregos mais bem remunerados. (ROSA, 2011, p. 7).

Ficou latente, desde o primeiro encontro que o passo primordial para podermos entender como os/as alunos/as se relacionavam com a diferença (alteridade) na sala de aula, era entender a relação desdes com suas próprias identidades, todavia, como tratase de uma pesquisa voltada para produção de uma dissertação, onde os prazos são curtos e diante da dificuldade que notamos em alguns alunos/as em expressarem-se verbalmente, embora não seja o usual, decidimos elaborar um questionário semiestruturado para levantar algumas informações pertinentes, sem deixar de lado o debate e o diálogo.

Nesse processo, duas perguntas produziram um grande impacto sobre o grupo, a primeira referente aos motivos que os/as levaram a cursar o Ensino Normal Médio, onde apenas uma estudante alegou ter escolhido o curso porque "sempre quiz ser professora" Isaura (18 anos), enquanto os demais alegaram terem iniciado o Normal 
Médio para não serem transferidos para uma Escola Integral (também conhecida como Escola de Referência) ${ }^{12}$.

Foi o caso, por exemplo, dos alunos José13 (19 anos): _ "Não queria ficar na escola de referência, a única opção foi vim fazer o curso normal médio" e Sandro (21 anos): "Por não querer passar o dia todo em escola de referência”.

As alegações dos/as alunos/as nos mostraram uma resistência com relação ao modelo de escola de tempo integral adotado pelo Estado, principalmente em relação ao período de permanência na escola, resistência esssa que tinha como justificativa, na maioria dos casos o fato de que eles/as ajudavam com as tarefas do lar, sendo uma das alunas, inclusive, já casada, o que inviabilizava a permanência em período integral na escola.

Constatamos, também, uma indignação por parte dos mesmos quando referiam-se ao fato que seu direito de escolha tinha sido desrespeitado, situação em que fica clara a já mencionada "dicotomia" existente dentro do próprio sistema educacional público, onde é feita uma diferenciação entre as escolas, sendo umas (como o próprio nome aponta) consideradas de "referência", para as quais são destinados maiores recursos e outras, as regulares, exibidas como "última alternativa".

A outra questão levantada foi com relação a proporção entre "negros", "brancos" e "pardos" nas salas de aula da escola e, em especial, no Ensino Normal Médio. De plano todos concordaram que existiam mais alunos brancos e pardos do que negros, tendo a maioria dos alunos do grupo se declarado "parda", sob a alegação de que era a cor que constava em seus registros de nascimento.

Apenas um aluno declarou-se negro, embora aos olhos de um observador mais atento não haja muita diferença entre ele e alguns dos que se declararam pardos, assim como não há uma diferença significativa (nos referindo exclusivamente ao fenótipo) entre alguns declarados pardos e os que se afirmaram brancos, mostrando uma sintonia 
com os argumentos defendidos tanto por (FRY, 2005) quanto por (MUNANGA, 2014), quando ambos fazem referência à dificuldade de se definir quem é negro num país marcado pela miscigenação, como o Brasil, onde o ser negro e o ser branco são mais uma questão de escolha política e social do que uma determinação biológica.

Essa contradição entre as declarações dos alunos, ilustra bem o que dissemos acima, pois os mesmos alunos que se declararam "pardos" (8/12) também disseram que existiam mais alunos "brancos" na turma, justificando tal afirmação sobretudo através da “observação", como fizeram (JOSÉ, 19) que questioando sobre como chegou a conclusão que existiam mais pessoas "brancas" que "negras" na sala, respondeu que chegou a conclusão pela "observação, durante os 4 anos de convivência".

Enquanto a aluna (EVA, 16), ao ser inquirida sobre a mesma questão, alegou que: _ "Por que a maioria das pessoas da sala são brancas e percebe-se através da observação".

Em poucos momentos, entretanto, a palavra "negro" foi empregada pelos alunos, sendo utilizadas expressões como "pardo/a", "moreno/a", como fez a aluna (MÁRCIA, 18 anos), ao narrar um episódio ocorrido durante o estágio supervisionado numa turma de ensino infantil, no qual precisou intervir, "porque uma menininha estava chorando, porque a outra amiguinha disse que se ela brincasse com o coleguinha que era moreno, não ia querer mais brincar com ela e que ela ia ficar morena também. [grifo nosso].

É interessante observar que mesmo tendo uma atitude aversa ao preconceito mostrado pela "menininha", Márcia usa a palavra "moreno" ao invés de "negro" para caracterizar a outra criança, mesmo que ao falar aponte para sua própria pele (ela declarou-se branca) e diga que a "cor não define quem aprende ou não", nos remetendo ao "etnocídio discursivo" da palavra negro, conforme afirma Kabenguele Munanga, no seu livro Rediscutindo a mestiçagem no Brasil.

A constatação dessa barreira com relação ao uso da palavra "negro" por parte dos/as alunos/as, aponta para existencia de um imaginário socialmente construído e 
situações veladas que são reproduzidas, tornando fulcral o que se conheça os princípios que permeiam o cotidiano escolar, com perspectiva da provisioriedade do mesmo, mostrando a necessidade de repensarmos conceitos como democracia, igualdade e racismo, possibilitando que os/as estudantes conheçam outras visões de mundo.

$\mathrm{E}$ assim, ao tomarmos a escola como "[...] fundamental no processo de construção identitária dos estudantes, na medida em que os processos de identidade e diferença se traduzem em operações de inclusão e de exclusão, em relações de pertencimento ou não pertencimento" (SANTIAGO et al., 2013, p. 34), somos levados a crer que é essencial, nesse contexto de (re)descoberta/busca identitária que a escola e o/a professor/a possam ser capazes de promover práticas e discussões que levem a uma ressignificação de (pre)conceitos e esteriotípicos enraizados numa tradição escolar onde a diferença era vista como "algo a ser consertado".

\section{Considerações Finais}

Iniciamos esta pesquisa sob a crença que a Lei 10.639/03 possui uma dimensão que ultrapassou sua proposta inicial, ou seja, a inserção da História e da cultura afrobrasileira na educação básica, tratando-se de uma tentativa de reforma educacional ambiciosa, à medida que delega à Escola a tarefa, não só de tentar corrigir as "injustiças históricas" com relação aos afro-brasileiros, mas também de buscar a promoção de relações "étnico-raciais" positivas, mostrando, assim, que ainda não deixamos de lado a tradição de querer resolver as demandas sociais através de decretos, incapazes por si só, mudar as práticas vigentes.

Isso porque, tais mudanças exigem que haja uma ressignificação de conceitos por parte dos agentes que irão ser responsáveis por transformar a lei em prática, e este não é um processo simples, pois envolve a reflexão e a substituição, de "verdades", 
"valores", paradigmas e pressupostos que foram construídos/formulados ao longo da vida, levando assim, ao abandono da área de conforto em prol do desconhecido, razão pela qual, nem todos estão dispostos ou preparados a assumir essa nova postura.

Substituir (ressignificar) as práticas pedagogias e educacionais tradicionalmente instituídas, onde a diversidade é lida como "[...] algo que é necessário corrigir, com um olhar que a reconhece sem a querer conhecer" pela "adoção de um olhar inter/multicultural não só como filosofia educativa, mas também como projeto a realizar" (STOER; CORTESÃO, 1999, p. 46), torna-se ainda mais difícil quando a proposta para fazer essa ressignificação vem de fora, ou seja, quando o desejo ou a necessidade de refletir sobre os conceitos pré-estabelecidos não partem de uma motivação do indivíduo.

Tem-se, assim, o que (STOER; CORTESÃO, 1999, p. 21) vão chamar de “professor daltônico cultural”, que é aquele "que não será sensível à heterogeneidade, ao arco-íris de culturas que tem nas mãos quando trabalha com seus alunos na escola" e, desse modo, voltamos à questão inicial, de que a lei, por si só, não basta para promover mudanças efetivas nas relações entre os idivíduos, neste caso, os alunos em sala de aula.

Sempre haverá quem diga que 13 anos é tempo insuficiente para ocorrerem transformações significativas tanto na sociedade quanto nas representações e práticas individuais com relação à aceitação da diversidade, não discordamos, mas perguntamos: as ações e políticas afirmativas tomadas até então tem realmente ajudado a promover tais mudanças?

Não podemos afirmar. O que acreditamos é que as relações de igualdade e solidariedade entre grupos socioculturais diferentes precisam ser construída, assim como foram as desigualdades e exclusões e esse é um processo que demanda grandes mudan- 
ças não só na estrutura política, social e econômica do país, como também e, principalmente, na forma como os indivíduos enxergam a si e aos outros, sendo estes últimos, conforme discorremos acima, fatores sobre os quais acreditamos que as leis exerçam pouca ou nenhuma influência significativa.

Mesmo as ações afirmativas do Estado, possuem uma natureza ambígua neste processo, pois ao passo que visam diminuir as assimetrias sociais, reforçam os discursos racialistas, do qual são dependentes, razão pela qual qualquer previsão que façamos sobre o caminho das relações "étnico-raciais” no Brasil, não passará de mera especulação.

Por último, é importante ressaltarmos que esse é um tema que gera muito mais questionamentos que respostas, afinal, seremos capazes de superar o ressentimento causado por décadas de uma violenta segregação humana em prol do ideal de uma sociedade mais igual? Algum povo será?

Paira a dúvida, então.

\section{Notas:}

${ }^{1} \mathrm{O}$ atual Ensino Médio já recebeu o nome de Segundo Grau, Científico e Ensino Secundário.

${ }^{2}$ Em tal contexto, Colégio Pedro II talvez tenha sido o símbolo maior dessa "segregação", pois "[...] foi criado com o propósito de formar as elites nacionais, os altos quadros políticos, administrativos e intelectuais do país” (BRASIL, 2013, p. 07).

${ }^{3}$ No Brasil, as pressões exercidas pelos movimentos sociais populares nos grandes centros urbanos e industriais do país, como São Paulo, entre o final dos anos 1940 e os anos 1960, levaram à expansão das oportunidades educacionais e à integração formal do ensino primário ao primeiro ciclo do ensino médio, o antigo ginásio. Ironicamente, foi o governo militar, por meio da Lei $\mathrm{n}^{\circ}$ 5.692/71, que introduziu formalmente a mudança, fixando a obrigatoriedade do ensino comum de oito anos. In: (BRASIL, 2013, p. 19).

${ }^{4}$ Citamos como exemplos, o reconhecimento do direito a terra de comunidades quilombolas e a abertura do debate acerca da visão do Brasil como uma país multirracial e multicultural, desafiando o ideal da mestiçagem.

${ }^{5}$ A Lei 10.639/03 e posteriomente a Lei 11.645/08 vêm alterar a Lei de Diretrizes e Bases da Educação, de 1996, acrescentando os arts. 26-A, 79-A e 79-B, trazendo, juntamente com as Diretrizes

Cadernos de Pós-graduação, São Paulo, v. 17, n. 2, p. 121-140, jan./jun. 2018. 
Curriculares Nacionais para a Educação das Relações Étnico-Raciais e para o Ensino de História e Cultura Afro-Brasileira e Africana, orientações mais explícitas para que as heranças culturais dos povos que contribuíram para a formação do país sejam tratadas de forma igualitária nas instituições escolares, ao tornar obrigatória a inclusão do Ensino da História e da Cultura Afro-brasileira e Africana e dos povos indígenas, em todos os níveis da educação do país.

${ }^{6}$ Para saber mais sobre o tema, mudança, tradição e inovação ver: HOBSBAWN, Eric; RANGER, Terence. (org) A invenção das tradições. 4e. São Paulo: Paz e Terra, 2006.

${ }^{7}$ O conceito de significante vazio é trabalhado por Ernest Laclau, no livro A razão populista.

${ }^{8}$ Aliás, o fato da Lei 10.639/03 não mencionar os povos indígenas, que assim como os afrobrasileiros, são considerados sujeitos a quem foi negada uma reprsentação igualitária na História do Brasil, bem como a sua posterior inclusão, através da Lei 11.645/08, mostra essa cadeia de equivalências e como o centro de poder pode ser deslocado se um grupo conseguir juntar as condições necessárias para impor suas reividicações ante o Estado e a sociedade.

${ }^{9}$ Informação verbal. Aula ministrada em 17/03/2015. 1 ${ }^{\text {a }}$ Turma de Mestrado em Educação da Universidade de Pernambuco, Campus Mata Norte.

${ }^{10}$ Ao menos até as décadas de 1960-70, quando tem lugar as pesquisas da UNESCO e o fortalecimento dos movimentos negros. Para saber mais ver: FRY, Peter. A persistência da raça: ensaios antropológicos sobre o Brasil e a África austral. Rio de Janeiro: Civilização Brasileira, 2005.

11 Modalidade de ensino que, ao nosso vê, produz uma categoria de estudantes que classificamos como "hibrida", dentro do universo escolar, pois ao mesmo tempo em que estão cursando as disciplinas obrigatórias para conclusão do Ensino Médio, também estão sendo preparados para se tornarem futuros professores.

${ }^{12}$ Modalidade na qual os alunos permanecem os dois turnos, manhã e tarde, na escola.

${ }^{13}$ Os nomes utilizados neste artigo são todos ficticios, afim de preservar a identidade dos participantes da pesquisa.

\section{REFERÊNCIAS}

RANTES, Adlene Silva. Processos de racialização nas escolas primárias pernambucanas (19111945). 2014. 255 f. Tese (Doutorado) - Universidade Federal da Paraíba (UFPB), João Pessoa, 2014.

BRASIL. Secretaria de Educação Básica. Formação de professores do ensino médio, etapa I caderno $I$ : ensino médio e formação humana integral / Ministério da 
Educação,Secretaria de Educação Básica; [autores : Carmen Sylvia Vidigal Moraes... et al.]. - Curitiba: UFPR/Setor de Educação, 2013. 51p. : il. algumas color., retrs.

FRY, Peter. A persistência da raça: ensaios antropológicos sobre o Brasil e a África austral. Rio de Janeiro: Civilização Brasileira, 2005.

KOFF, Adélia Maria Nehme Simão e. Reinventado a escola: relato de uma experiência de trabalho com projetos. In: CANDAU, Vera Maria. (Org.) Didática crítica intercultural: aproximações. Petrópolis, RJ: Vozes, 2012.

LACLAU, Ernest. Emancipação e diferença. Rio de Janeiro: Ed.UERJ, 2011.

MUNANGA. A difícil tarefa de definir quem é negro no Brasil. Entrevista. Revista Estudos Avançados, 18 (50), 2014. p. 51-56. Disponível em: $<$ http://www.scielo.br/scielo.php?script $=$ sci serial\&pid $=0103$ 4014\&lng=pt\&nrm=iso $>$. Acesso em: 03 out. 2015.

ROSA, Renata Vidica Marques da. Feminização do Magistério: Representações e espaço docente. Revista Pandora Brasil. Edição especial n 4 - Cultura e materialidade escolar, 2011. Disponível em: http://revistapandorabrasil.com/revista_pandora/materialidade/renata.pdf. Acesso em: 03 out. 2015.

SANTIAGO, Mylene Cristina et al. Educação intercultural: desafios e possibilidades. Petrópolis, RJ: Vozes, 2013.

SCHURSTER, Karl. Estado e Políticas Educacionais no Brasil. Aula ministrada em 17/03/2015, para a $1^{\text {a }}$ Turma do Mestrado em Educação da Universidade de Pernambuco, Campus Mata Norte.

STOER, Stephen; CORTESÃO, Luiza. Levantando a pedra:. da pedagogia inter/multicultural às políticas educativas numa época de transnacionalização. Porto: Edições Afrontamento, 1999.

TORRES, Marcele Xavier; FERREIRA, Marcia Serra. Currículo de História: Reflexões sobre a problemática da mudança a partir da Lei 10.639/03. In: MONTEIRO, Ana 
Maria [et al]. Pesquisa em ensino de história: entre desafios epistemológicos e apostas políticas. Rio de Janeiro: Mauad X: Faperj, 2014.

recebido em 29 jun. 2018 / aprovado em 23 out. 2018

\section{Para referenciar este texto:}

SANTANA, N. M. A. A lei 10.639/03 e as relações étnico-raciais no ambiente escolar: mudanças e permanências. Cadernos de Pós-graduação, São Paulo, v. 17, n.2, p. 121-140, jul./dez. 2018. Disponível em: <https://doi.org/10.5585/cpg.v17n2.8865>. 